\title{
The next wave in family practice
}

Y

ou know physicians are interested in a topic when a presentation draws a crowd so large that it creates a fire hazard. Evidently, family doctors are very interested in practice-based research. A session on the top research studies that will have an impact on clinical practice for family physicians was so overcrowded that it had to be moved to a larger room Nov. 15 at the Family Medicine Forum in Toronto, Ontario.

"Some of the people in that room came for the evidenced-based guidelines useful to their practices," says Dr. Elizabeth Muggah, a family physician who moderated the session. "We are a discipline that crosses so many fields. If you had to read all that stuff yourself, it would be very hard. So the notion of someone synthesizing that data for you is great."

Equally encouraging is that more family doctors appear interested in actually conducting research to improve their practices, rather than waiting for it to trickle down from the ivory tower, notes Muggah, a new career scientist with the C.T. Lamont Primary Health Care Research Centre in Ottawa, Ontario.

It's about time that primary care physicians take generating evidence more seriously, says Dr. David White, an associate professor in the Department of Family and Community Medicine at the University of Toronto. "Family medicine has been late to the table as far as producing its only body of knowledge."

Research is typically conducted on a narrow topic by specialists in a particular field, so it shouldn't be too surprising that the evidence produced is more useful to fellow specialists than to general practitioners.

"There are hypertension specialists and cardiologists doing work on chest pain. Low back pain was the domain of orthopedic surgeons, often, or neurosurgeons. Diabetes was dominated by endocrinologists," White says. "And what would happen was you get research and guidelines

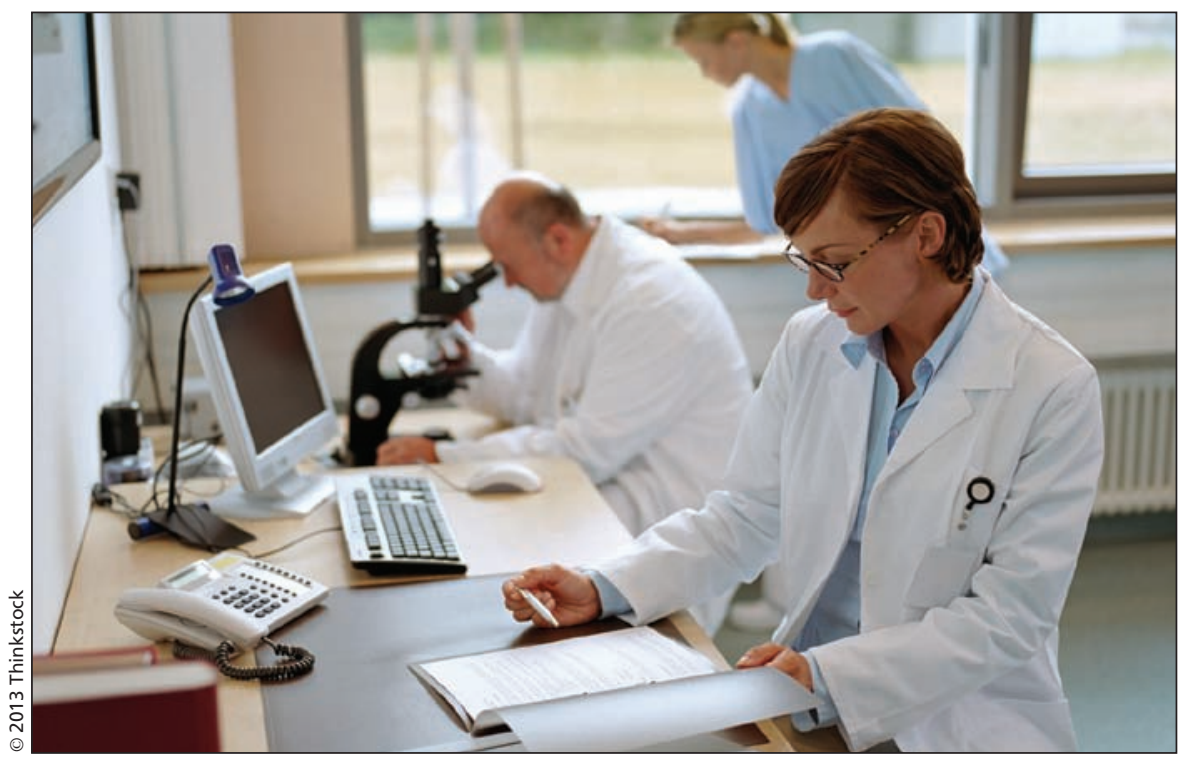

It's often held that the high cost of conducting research puts such work out of the reach of the average physician, but many believe that family doctors can undertake studies that benefit general practice.

that were from those groups and were great, if you were in a specialty clinic and not looking after everything. The time frame is different. The scope of practice is different. And so constantly we would feel like it wasn't practical."

Research conducted within family practices, on the other hand, can provide enormous practical benefit to general practitioners, White and colleagues noted while skimming through findings from a number of practice-based studies.

For example, recent research has indicated that more than $40 \%$ of patients don't take the antibiotics prescribed for them by family doctors for lower respiratory tract infections. Of course, this might not be such a bad thing, as research has also indicated the health outcomes for such patients differs little from those who do take the antibiotics.

Practice-based research can also help family doctors to better diagnose chronic obstructive pulmonary disease, and more effectively screen for a number of other common conditions, such as hypertension and colorectal cancer, the presenters noted.

It can even help physicians make decisions about how they allocate physical space in their offices. For instance, it turns out that automated blood pressure measurements conducted in quiet, private rooms (as recommended by device manufacturers) aren't more accurate than measurements taken in nonprivate areas where there is some noise. Likely that's welcome news for busy practices with limited space.

So why aren't more family doctors involved in such studies?

One of the biggest obstacles is their working environment, says Muggah. Traditionally, family doctors have worked independently in isolated practices, while being paid on a fee-for-service basis, leaving them little time or financial latitude to undertake research.

But that's changing, Muggah says. "In Ontario, but in the rest of the jurisdictions as well, as we move toward practices that are groups, that are interdisciplinary, where there is some protected time, even to do your own quality improvement, I think that the notion of practice-based research is growing. It's going to be a byproduct of moving doctors into groups." - Roger Collier, CMAJ

CMAJ 2013. DOI:10.1503/cmaj.109-4351 